\begin{tabular}{|c|c|c|}
\hline UÁQUIRI & PPG \\
\hline & Revista do Programa de Pós-Graduação em Geografia \\
UÁQUIRI - PPGGEO, v. 2, n. 1, p. 178 - 190, ano 2020 & \\
Home page: https://periodicos.ufac.br/index.php/Uaquiri & ISSN 2675-4088 \\
\hline
\end{tabular}

\title{
ANÁLISE SOCIOESPACIAL, CULTURAL E AMBIENTAL DAS REGIONAIS ALTO E BAIXO ACRE: UM RELATO DE EXPERIÊNCIAS.
}

Analine de Souza $\mathrm{Cacau}^{1}$, Karolayne Almeida de Souza ${ }^{2 *}$, Lucas Fernandes ${ }^{3}$, Vitória de Melo Brasil $^{4}$, Alexsande de Oliveira Franco ${ }^{5}$, Silvio Simione da Silva ${ }^{6}$

\begin{abstract}
${ }^{1}$ Discente do curso de Geografia Licenciatura da Universidade Federal do Acre, Rio Branco, Acre, Analinedesouza06@gmail.com; ${ }^{2}$ Discente do curso de Geografia Licenciatura bolsista do Grupo PET Geografia da Universidade Federal do Acre, Rio Branco, Acre, layne.capixaba@gmail.com; ${ }^{3}$ Discente do curso de Geografia Licenciatura, da Universidade Federal do Acre, Rio Branco, Acre, lucasgeofernandes@gmail.com; ${ }^{4}$ Discente do curso de Geografia Licenciatura, bolsista do Grupo PET Geografia da Universidade Federal do Acre, Rio Branco, Acre, melo.vitoria236@gmail.com; ${ }^{5}$ Professor Doutor da Universidade Federal do Acre, Centro de Filosofia e Ciências Humanas, Rio Branco, Acre, aofrancoufac@hotmail.com; ${ }^{6}$ Professor Doutor da Universidade Federal do Acre, Centro de Filosofia e Ciências Humanas, Rio Branco, Acre, ssimione@gmail.com.
\end{abstract}

O presente trabalho tem como objetivo relatar experiências realizadas em atividades práticas de campo das disciplinas Geografia do Acre e Geoecologia nos municípios das regionais Alto e do Baixo Acre: Capixaba, Xapuri, Epitaciolândia, Brasiléia e Assis Brasil. Para tanto, utilizou-se para realização do trabalho levantamento de referencial teórico que abordasse aspectos relacionados ao relato de experiências, observações e análises. A interdisciplinaridade das disciplinas proporcionou relacionar aspectos históricos, ambientais, sociais e espaciais dos lugares visitados, interagindo a teoria evidenciada em sala de aula com a prática em campo. A contribuição dessa atividade foi significativa para a construção do conhecimento a respeito do território acreano e suas diversas características.

Palavras-chave: Relato de experiência; Tríplice Fronteira; Acre.

\section{SOCIO-SPATIAL AND ENVIRONMENTAL ANALYSIS OF THE HIGH AND LOW ACRE REGIONS: AN EXPERIENCE REPORT.}

\begin{abstract}
The present work aims to report experiences carried out in practical field activities of the disciplines Geography of Acre and Geoecology in the municipalities of the High and Low Acre regions Capixaba, Xapuri, Epitaciolandia, Brasileia and Assis Brasil. For this purpose, a theoretical reference survey was used to carry out the work that addressed aspects related to the reporting of experiences, observations, and analyzes. The interdisciplinarity of the disciplines allowed to relate historical, environmental, social and spatial aspects of the places visited, interacting the theory evidenced in the classroom with the practice in the field. The contribution of this activity was significant for the construction of knowledge about the Acre territory and its diverse characteristics.
\end{abstract}

Keywords: Experience report; Triple Frontier; Acre. 


\title{
ANÁLISIS SOCIO-ESPACIAL Y AMBIENTAL DE LAS REGIONES DE ALTO Y BAJO ACRE: UN INFORME DE EXPERIENCIA.
}

\begin{abstract}
RESUMEN
El presente trabajo tiene como objetivo informar experiencias realizadas en actividades prácticas de campo de las disciplinas Geografía de Acre y Geoecología en los municipios de las regiones de Alto y Baixo Acre Capixaba, Xapuri, Epitaciolândia, Brasiléia y Assis Brasil. Para este propósito, se utilizó una encuesta de referencia teórica para llevar a cabo el trabajo que abordó aspectos relacionados con el informe de experiencias, observaciones y análisis. La interdisciplinariedad de las disciplinas permitió relacionar aspectos históricos, ambientales, sociales y espaciales de los lugares visitados, interactuando la teoría evidenciada en el aula con la práctica en el campo. La contribución de esta actividad fue significativa para la construcción de conocimiento sobre el territorio Acre y sus diversas características.
\end{abstract}

Palabras clave: Informe de experiencia; Triple frontera; Acre.

\section{INTRODUÇÃO}

As experiências, representadas pela observação e análise a partir das aulas de/em campo são muito importantes para a construção do ensino e aprendizagem. Pois trata-se de um método de ensino, segundo (RODRIGUES; OTAVIANO, 2001) que auxilia na aproximação das aulas teóricas com a prática. As atividades em campo/práticas possuem em sua estrutra de ensino a possibilidade dos discentes abordarem os desafios e os problemas de forma eficiente, pois podem usar o conhecimento teórico de forma ativa para encontrar ou sugerir soluções.

A atividade em campo que se refere as experiências relatadas no presente trabalho foi realizada em cinco municípios do estado do Estado do Acre, a saber: Capixaba, Xapuri, Epitaciolândia, Brasiléia e Assis Brasil. As atividades se basearam na vivência teórica em sala de aula para posteriormente imergir em campo. Nessa direção as atividades foram fundamentadas na observação e análise das práticas econômicas, sociais, espaciais, culturais e ambientais dentro do espaço rural e urbano. Além do mais, é importante mencionar que a dinâmica das cidades, a relação com as fronteiras do Brasil, Peru, Bolívia (a integração territorial e econômica da tríplice fronteira, a dinâmica de movimentação de pessoas entre esses três países, além de realizarmos apontamentos a respeito dos desafios, percalços e potencialidades das cidades percorridas) e ainda a fala dos diferentes atores sociais (Sindicato dos Trabalhadores Rurais - STR de Xapuri, o grupo Cáritas e a Polícia Rodoviária Federal) dessa embrincada rede socioespacial também foram abordadas.

Esse, é por natureza, um trabalho interdisciplinar entre as disciplinas curriculares Geografia do Acre e Geoecologia, desenvolvimento e sustentabilidade. Segundo (THIESEN, 2008) a interdisciplinaridade busca o diálogo com as diversas áreas do saber para evitar a 
fragmentação ou especialização do conhecimento, sendo assim, o trabalho procura analisar as questões das dinâmicas Amazônicas e Acreanas nos diferentes níveis de organização.

O trabalho está organizado pelos trechos visitados na aula de campo e as atividades desenvolvidas, sendo eles: a) Rio Branco - Xapuri, b) Xapuri - Assis Brasil e c) Assis Brasil Brasileia / Epitaciolândia.

Doravante, o objetivo do presente trabalho foi relatar experiências realizadas em atividades práticas de campo com o intuito de fazer uma análise socioespacial e ambiental das regionais Alto e Baixo Acre nas disciplinas: Geografia do Acre e Geoecologia.

Qual a metodologia? Qual abordagem? Qual forma de pesquisa? Qual forma de coletar os dados?

\section{DESENVOLVIMENTO}

\subsection{O percurso em campo}

Durante a trajetória da aula de campo, foram feitas paradas em locais estratégicos para melhor visualização da área, bem como realização de algumas atividades ministradas pelos docentes e/ou convidados da regional. Saindo da Universidade Federal do Acre em Rio Branco, foi realizada primeira parada no município de Capixaba, na usina de cana de açúcar, Álcool Verde. Ainda no primeiro dia, foi realizada atividade no campus do IFAC (Instituto Federal do Acre) em Xapuri.

No segundo dia foi feito uma visita a Alfândega em Assis Brasil na fronteira entre Brasil e Peru e posteriormente uma visita a Paróquia de Assis Brasil em um encontro com representantes do grupo Cáritas do próprio município. Ainda no mesmo dia, foi possível visitar inanpari, no Peru, observando a realidade estrangeira. Por fim, no terceiro dia em Brasiléia ocorreu um encontro com uma representante do Movimento sindical de mulheres camponesas de Pando (BO) (figura 1).

O percurso em campo seguiu os trechos: Rio Branco - Xapuri e Xapuri - Brasiléia Assis Brasil de forma a aglutinar as experiências possíveis para que discentes pudessem relacionar a teoria e a prática. 
Figura 1: Trajeto da atividade de campo

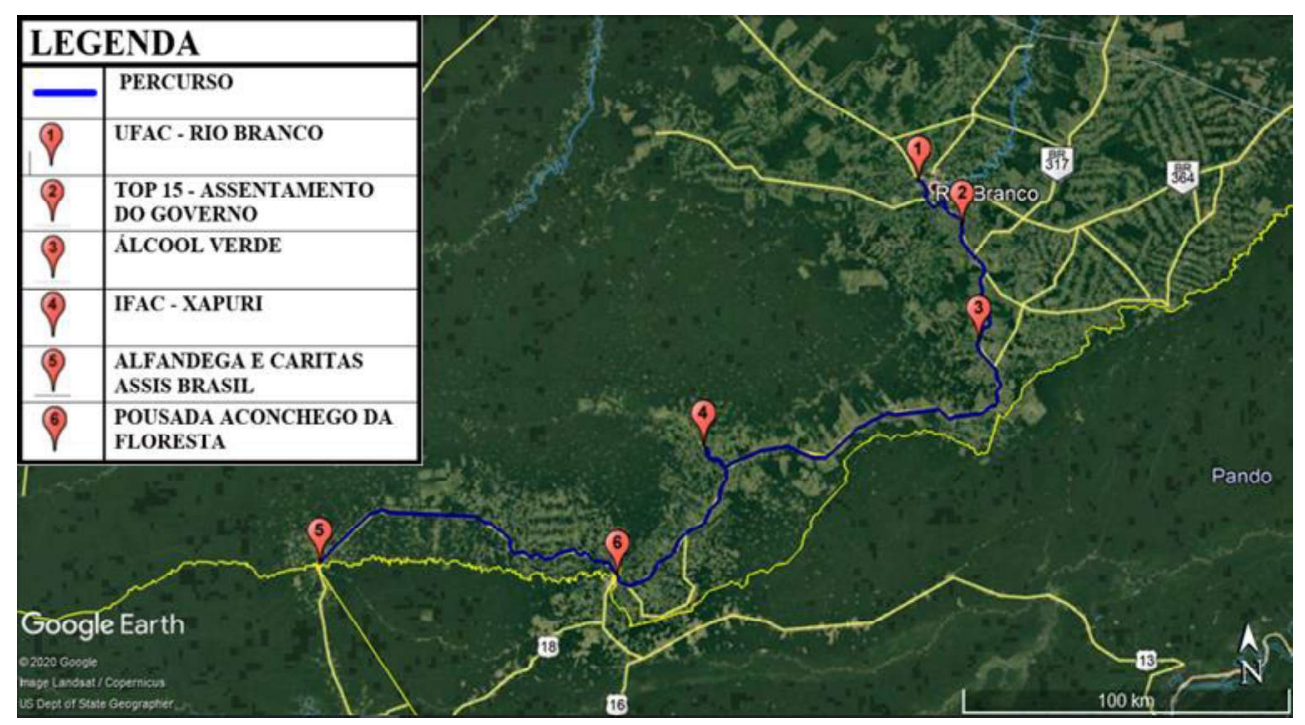

Fonte: Google Earth (2019)

Na sequência são apresentadas no contexto de cada trecho as análises propostas, a saber, socioespacial, cultural e ambiental.

\subsection{Trecho Rio Branco - Xapuri}

Nesse trecho foi possível realizar uma parada na cidade do município de Capixaba. Esse é um município sem a ligação histórica com o rio, tendo uma ligação maior com a rodovia. Configura-se em um percurso com áreas de fazenda, logo após a área urbana, temos uma pequena entrada que dá acesso a fronteira com a Bolívia, o chamado ramal "Brasil - Bolívia", na qual se encontra uma fronteira "seca" (que são fronteiras que apresentam uma delimitação simbólica sem uma divisão por um elemento natural), que é o caso da fronteira do município de Capixaba com a Bolívia, só existe um marco simbólico que divide os dois territórios, não um elemento natural em sí.

\section{Álcool Verde}

Ainda em Capixaba, o projeto Álcool Verde foi elaborado na década de 1980, mas só foi reativado no Governo da Frente Popular (FPA) que fez um convenio com o grupo "Farias" do Nordeste mais especificamente de Alagoas, sendo um empreendimento subsidiado. Atualmente, o subsídio foi retirado, dessa forma, a usina encontra-se praticamente parada e onde era local de canaviais em muitos pontos temos a presença de pastos. A tendência seria 
uma cultura intensiva no uso de insumos e mão-de-obra, com ocupação de áreas capoeiras e de pastagens em degradação localizadas a distâncias de até $50 \mathrm{~km}$ da agroindústria (ACRE/ZEE, 2006), no entanto, foi além, e algumas áreas com vegetação foram desmatadas.

De acordo com a análise da paisagem podemos notar a mudança que ocorreu no espaço ao redor da fábrica, pois como foi citado anteriormente aconteceu o desmatamento para a plantação da cana-de-açúcar, esta possuía vegetação, mas agora por conta do desmatamento possui alguns problemas ambientais, além de expropriação de comunidades menos favorecidas que residia no local e trabalhavam para o empreendimento na maior parte das vezes como trabalhador temporário. Para Farias e Araújo (2011, p. 19) “muitos já estavam ligados com o trabalho na terra, pois possuem lotes nos assentamentos ou moram com parentes que vivem da agricultura e/ou pecuária. No caso das mulheres, a maioria se ocupava no trabalho doméstico".

Nessa direção, Teixeira, Silva e Farias (2017, p. 150) menciona:

A utilização e ocupação indevida dos espaços geográficos compromete a sustentabilidade ecológica em alguns setores, o que promove mudanças na dinâmica ambiental e no fluxo de matéria e energia, bem como no modo de vida das comunidades atingidas. Nessa perspectiva, faz-se necessário a implantação de propostas e ações voltadas ao planejamento ambiental. [...].

O processo de produção da cana funcionava de duas formas: a empresa quando foi aberta tinha uma área que era parte da empresa, uma área de aproximadamente 600 hectares, com os assentamentos Zaqueu Machado e Alcoobras, eles arrendavam lotes dos assentamentos, onde muitos produtores foram assentados, mas de fato não produziram, ou apenas moravam ou iam morar em Capixaba. Muitos fazendeiros que tinham terras próximos a Álcool Verde, também entraram no empreendimento que era uma experiência da Parceria Público, Privado, Comunitário (PPPC), mas por diversos problemas, entre os quais o solo. Dessa forma, o projeto não foi bem sucedido, pois primeiro a cana-de-açúcar causa um esgotamento muito forte da terra e os produtores saíram e muitos deles não produziram nada, sendo assim, com a decadência da empresa, os fazendeiros voltaram as pastagens e retomaram a atividade pecuária.

De acordo com análise feita na aula de campo, o empreendimento sofreu restrições, mas mesmo assim se expandiu, porém, enfrentou problemas em relação ao mercado interno Acreano que é pequeno comparado aos grandes centros agrícolas (Centro-Oeste e Sudeste), dessa forma não temos mercado consumidor que absorva a demanda, e a má estrutura de circulação desfavorece o processo de escoamento do produto e pela lógica do capital ele se instala aonde há maior possibilidade de circulação de mercadorias e reprodução mais rápida. $\mathrm{O}$ transporte, e mesmo o conjunto de fatores com caráter técnico, perde sua importância 
proporcional em relação aos outros fatores de localização, no entanto, continua indispensável para o bom funcionamento do processo (FISCHER; FIRKOWSKI; SPÓSITO, 2008).

Dessa forma, os autores nos apontam que tanto a localização do empreendimento como o meio de transporte que se tem ao redor é de extrema importância pois a produção tanto se favorece com a proximidade da matéria prima como também se faz necessário um sistema de transporte adequado para a circulação de mercadorias.

O projeto tinha como intenção o escoamento pela interoceânica, que seria pelo oceano pacífico, essa vinculação com a Bolívia e o Peru era o grande discurso, a zona de processamento para a exportação com outros empreendimentos buscando essa ligação internacional. Dessa forma, criou-se uma expectativa no álcool, com a possível implementação da estrada de ferro fazendo assim a integração da tríplice fronteira. Porém, a construção da estrada não vingou e pela logística de produção o empreendimento da Álcool Verde não foi bem sucedido.

Esse conjunto de ideias a respeito da integração internacional Brasil- Peru- Bolívia já é algo antigo, data do governo de Wanderley Dantas (período de governo), com incentivos fiscais para produção em terras acreanas com o discurso da ligação com esses países.

[...] No Acre, já no período pós-1964 até 1970, inicia-se a adoção de política desenvolvimentista sob a ótica da expansão rodoviarista. Assim como noutras partes da Amazônia, as rodovias seriam os eixos difusores para a implantação da atividade agropecuarista, para o direcionamento de fluxo de investimentos e também para o povoamento, a partir da transferência de contingentes populacionais do Centro - Sul (REBOUÇAS; ALMEIDA e SILVA, 2008, p. 215).

Mesmo com a implantação de medidas incentivadoras, o projeto não teve um êxito pela falta de estrutura para rota de exportação e essa ligação é uma construção simbólica, por causa da infraestrutura das estradas, que não suportam o tráfego pesado impossibilitando essa rota de mercadorias pelas rodovias.

\section{A Fazenda "Três Meninas"}

Ao longo da estrada não foi observado diferença do trecho em comparação ao anterior. Temos pastagem e as plantações de milho. Também tivemos a oportunidade de conhecer a hotel fazenda "Três meninas" no quilômetro 125 na estrada de Xapuri, que se configura em um local de visitações e também estadia para pessoas que estão de passagem ou simplesmente vão para conhecer a fazenda, que oferece quartos para família e para casais e onde se pode realizar as refeições diárias, descansando e aproveitando a paisagem (figura 2). 
Figura 2: Imagem da fazenda " Três Meninas"

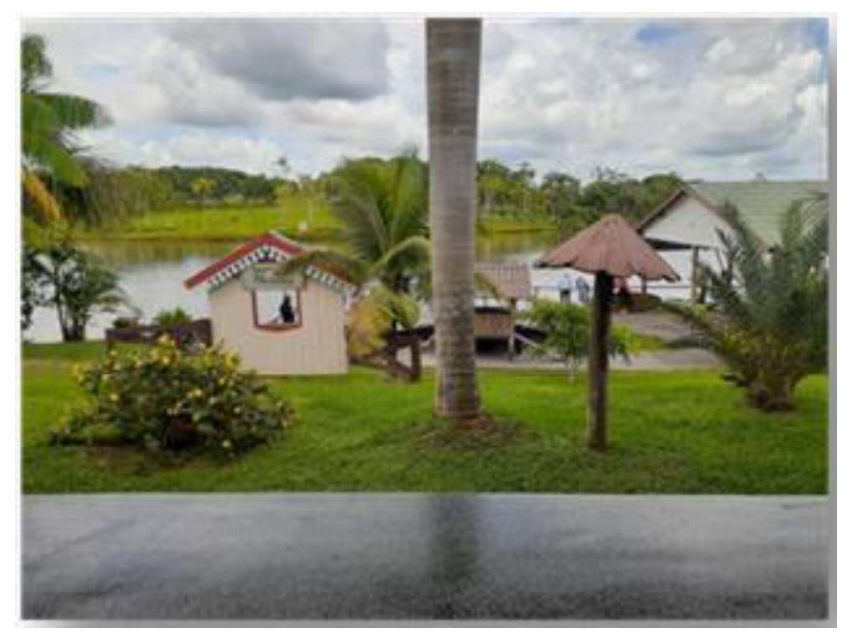

Fonte: Cacau (2019).

Observou-se que há a interação humana na transformação da paisagem do local para torná-lo agradável ao público, mas tem a presença de aspectos naturais para oferecer as pessoas a interação com a natureza e a oportunidade de saírem de seus cotidianos. É a transformação do rural e a aproximação da cidade e do campo, mas sem excluir a possibilidade de interação com os aspectos naturais.

\begin{abstract}
Há também uma nova onda de valorização do espaço rural, capitaneados por questões ecológicas preservação da cultura "country", lazer, turismo ou para moradia. Observa-se em todo mundo uma preocupação crescente com a preservação ambiental que estimulou o novo filão do turismo: o ecológico. A nova forma de valorização do espaço vem a remodelar as atividades ali existentes, em função da preservação ambiental e do atendimento aos turistas (SILVA; GROSSI, 1998, p. 166).
\end{abstract}

Dessa forma, a fazenda tornou-se um atrativo turístico e de lazer configurando essa transformação do espaço rural brasileiro estimulado pela preservação ambiental e pela busca das pessoas pela natureza como forma de sair do cotidiano das cidades e do trabalho.

\title{
2.3. Trecho Xapuri - Brasileia - Assis Brasil
}

\section{Sindicatos dos Trabalhadores Rurais - STRs: Fala da Dercy Thelles}

$\mathrm{Na}$ aula de campo tivemos a oportunidade de conhecer um pouco da história de uma extrativista e líder sindical de Xapuri que tem por nome, Dercy Thelles. Nasceu no seringal Boa Vista e iniciou sua militância no final da década de 1980 nos conflitos pela posse de terras entre os seringueiros e os fazendeiros da frente pioneira agropecuária. 
Assim, quando a frente pioneira agropecuária avançou sobre o território acreano, no final da década de 1960, encontrou aqui uma base estrutural produtiva agrária concretizada. Também já havia uma rede de cidades com uma estrutura urbana já avançada, com aparatos administrativos, jurídico e comercial consumados. Eram resultado da formação socioespacial da frente pioneira extrativista, que aí se apresentava decadente (SILVA, 2008, p. 175).

Sendo assim, os conflitos por terra se materializavam pois os seringueiros já estavam há muito tempo nas terras, vivendo seus cotidianos e reproduzindo seus modos de vida, a frente extrativista agropecuária chegou prioritariamente com incentivos fiscais do governo, principalmente na época de Wanderley Dantas (período de governo) e tenta a todo custo tirar esses seringueiros das suas terras, que nesse momento se caracterizavam mais como posseiros, pois não viviam apenas da extração do látex. Essa frente de ocupação dos fazendeiros segundo a fala da Dercy não consideravam que os seringueiros estavam ocupando essas terras e muitos usaram de meios violentos para expulsarem seringueiros de suas colocações.

O seringalista, ao vender o seringal aos seus novos donos - "os paulistas", desconsideravam a situação dos posseiros que já ocupavam estas terras por décadas consecutivas. Isso implicava que os novos donos promoveriam a "limpeza da área", isto é, a retirada dos posseiros (SILVA, 2008, p. 176).

A fala de sindicalista mostrou a luta em que ela entrou para a defesa das terras dos seringueiros para que esses continuassem a reproduzir seus modos de vida em suas colocações, dessa forma, salientou sobre o papel da igreja deles como escola que ensinava uma "teologia da libertação", na busca de mostrar para os posseiros o que estava acontecendo e para que eles se engajassem na luta pela sobrevivência de seus modos de vida e pelas suas terras, pois muitos fazendeiros usavam métodos ilegais para conquistarem as terras dos posseiros e através dos ensinamentos que eram para eles repassados através dessa teologia da libertação, puderam analisar o que estava de fato ocorrendo em suas vidas e assim não serem mais enganados.

Nessa situação, a pastoral católica da igreja da antiga Prelazia Acre- Purus (atual Diocese de Rio Branco), numa evangelização libertadora, sob orientação da "Teologia da Libertação" foi o ponto inicial para despertar, nesses posseiros, a consciência para a situação que estavam submetidos (SILVA, 2008, p.178).

Dercy também relembrou a chegada da Confederação Nacional dos Trabalhadores na Agricultura - CONTAG na região, que era uma delegacia que tinha chegado na região para a implantação dos Sindicatos dos Trabalhadores Rurais - STRs, onde relembra a criação do STRs 
de Brasiléia em 1975 e o STRs de Xapuri em 1977, no qual ela foi a segunda presidente e enfrentou vários problemas citados por ela como o machismo e a ditadura militar.

Outros fatores citados na na fala de Dercy se refere ao Centro dos Trabalhadores da Amazônia e o Conselho Nacional dos Seringueiros, órgãos responsáveis por propor políticas para o fortalecimento das questões trabalhistas e a organização dos sindicatos. Por fim, Dercy faz uma crítica em relação a reserva extrativista onde declara que a reserva deveria ser um modelo de reforma agrária, porém os lotes não proporcionaram subsídios necessários para a produção e organização econômica dessas famílias.

\section{Confederação Cáritas}

Em Assis Brasil foi feita uma palestra com dois representantes da Confederação Cáritas, uma instituição da igreja católica que realiza trabalhos sociais, mais especificamente cuidando da vulnerabilidade das pessoas, agora lidando com o fluxo migratório.

Ao iniciar as suas atividades, a Cáritas, atuou com o fluxo migratório dos haitianos quando ocorreu um terremoto no pais. Esta atuação não se deu efetivamente em Assis BrasilBR, mas sim em Iñapari-PE. Os representantes da Cáritas ainda informaram que eles não tiveram auxílio do governo peruano, desta forma a ajuda aconteceu apenas por parte da igreja. Vale ressaltar que mesmo sem apoio a ação aconteceu com a autorização do governo peruano, em um primeiro momento eles levavam a comida pronta para os haitianos, porém com o tempo eles alugaram uma casa e passaram a levar os mantimentos que eram conseguidos pelos fiéis da igreja católica.

Outras formas de ajuda que a Cáritas realizou foram: a) apoio emocional que deve ser prestado, pois a condição de vida acaba sendo muito precária o que abala o emocional daqueles que saíram de seus países; b) a organização da documentação para que eles prosseguissem o seu caminho pois, a cidade não oferecia estrutura para oferta empregos. Logo, o Acre foi apenas passagem e não o destino final dos mesmos.

Um desafio é o real apoio do poder público. A cáritas não possui verba para este tipo de finalidade, mas a ajuda das pessoas que são da igreja católica com o apoio de alguns fiéis de outras igrejas, tanto para a alimentação daqueles que estão no local oferecido pela igreja como para a passagem de ônibus para Brasiléia, pois a preocupação é que eles não seguissem a pé. Para ajudar na compra de passagem os haitianos acabavam fazendo alguns artesanatos para comercializar. 
Existe uma organização maior que a Cáritas que envolve a região de Madre de Dios, Acre e Pando - MAP, que estuda a entrada dos imigrantes e qual a sua origem. Havendo várias reuniões, em Puerto Maldonado-PE, Cobija-BO e em Rio Branco com foco na discussão do tema voltado para saber o melhor procedimento para lidar com estes imigrantes. A preocupação é que os imigrantes continuarem com o fluxo pois a estadia deles no local é inviável.

\section{Tríplice Fronteira Brasil - Peru- Bolívia}

A alfândega localizada em Assis Brasil, na rodovia 317, instalada pelo governo federal na fronteira entre Brasil e Peru, nos municípios de Assis Brasil-BR e Iñapari-PE conta com a presença de agentes da Polícia Federal que atuam na fiscalização de entrada e saída de veículos, produtos, pessoas e etc.

$\mathrm{Na}$ visita realizada pudemos conhecer a rotina de um dos agentes responsáveis pela segurança do local. O policial federal relatou como funciona o posto de atuação, falando sobre os desafios socioespaciais, políticas, localização e imigração da fronteira.

O Brasil possui uma extensa área de fronteira na qual, cada local age de acordo com sua região, podendo variar as formas de controle, sendo alguns mais ou menos rígidos, ou mais ou menos eficazes. Hoje, a forma de migração que existe naquele local é de entrada e saída de peruanos ou bolivianos, porém acabou se tornado uma rota de atuação para os coiotes que a utilizam como trajeto com destino aos Estados Unidos, já que os mesmos encontram facilidades de circulação nesta área. Esta mesma rota também foi local de intensa entrada de haitianos na época de maior imigração desta população e hoje há a entrada de venezuelanos que utilizam este percurso como área de passagem com destino ao Sul do país.

A estrutura da polícia federal apresenta uma hierarquia de funcionamento, na qual possui um órgão central, localizado em Brasília, as superintendências regionais e as delegacias descentralizadas. O local onde visitamos é um posto de atendimento, não podem realizar alguns serviços de imigração como: registro de estrangeiros, pedidos de residência, solicitação permanência ou até mesmo solicitação de trabalho, não emite documentos como por exemplo, passaportes. Este tipo de atendimento seria realizado através de delegacias ou de superintendências. $\mathrm{O}$ posto de atendimento, realiza alguns serviços no combate ao tráfíco de drogas, trabalhando em conjunto através de denúncias ou com serviço de inteligência. Apesar de não possuir estrutura de uma delegacia o posto está apto a realizar flagrantes de tráfico internacional de drogas, dentre outros crimes federais. 
Embora muito antigo em termos históricos, o tráfico de drogas mobiliza hoje um contingente de pessoas e um montante de recursos inéditos na história. Não há país na face da Terra que não esteja, de uma forma ou de outra, articulado na sua teia de poder[...] (HASESBARERT e GONÇALVES, 2006, p. 61)

Apesar do Brasil fazer fronteira com os três maiores produtores de drogas (Colômbia, Peru e Bolívia), pela logística de circulação, o estado do Acre é uma rota favorável para o tráfico de drogas, pois possui grandes fronteiras e fácil saída para outros estados e países. A relevância dessa rota dar-se-á pela guerra de facções que chegam inclusive nos municípios do interior do estado. Essa rota fronteiristica tem ganhado relevância, pois tem aumentado o fluxo de mercadorias e de pessoas imigrando de outros países. Essas fronteiras necessitam de dinâmicas diferentes de funcionamento, para cada tipo de problemas que se encontram nesses territórios.

O estado do Acre apresenta características de zona primária, sendo assim, todo o seu monitoramento é feito através de órgão federais, os quais fazem controle de acordo com sua área de atuação e realizam inúmeras ações no combate ao contrabando e descaminho, realizadas de forma conjunta com outras instituições como: Receita Federal, Ministério da Agricultura, Polícia Federal e etc.

Atualmente é observado um forte fluxo de imigração partindo da região Norte para a região Sul do Brasil e uma entrada predominante de imigrantes cubanos e mais recentemente de imigrantes venezuelanos, que percorrem uma rota que se inicia no estado de Roraima, segue pelo estado Acre, passando pelo Peru com foco de chegada no Uruguai. Registrou-se também a entrada de vários "coiotes" que saíram de Bangladesh, Paquistão e Índia, ingressaram com passaportes falsos, entraram por São Paulo, passando pelo Acre em direção aos Estados Unidos. Se tratando da entrada de imigrantes, foi registrado uma entrada em massa de haitianos entre 2014 e 2015, porém a alfândega de Assis Brasil faz entrega do visto com classificação do imigrante como refugiado, todo o restante dos procedimentos são realizados em uma superintendência ou nas delegacias mais próximas.

As condições de trabalho, que hoje se encontram na alfândega, relatada pelo policial federal que trabalha no local, se caracteriza por grandes desafios. Os reforços só são enviados, em situações de emergências. O serviço público de fronteira sofre com as condições precárias de estrutura, falta de reforços, e números reduzidos de funcionários e por conta da sua localização, que se encontra afastado dos grandes centros. Durante a forte onda de imigração, por exemplo, foi feito a tentativa de funcionamento por 24 horas, porém, foi constatado a falta 
de atendimento no período da noite, sugerindo o fechamento durante o mesmo turno, reduzindo assim, a quantidade de funcionários do local.

Entre as alfândegas localizadas nas cidades de Iñapari e Assis Brasil foi observado um fluxo de circulação considerada mais tranquila, por serem duas cidades de fronteiras conturbadas, na qual não se faz necessário a imigração da população nem a fiscalização de controle imigratório de ambos países. Assim ocorre situação semelhante em Cobija-BO, fronteira com a cidade de Brasiléia-BR, onde nota-se cidadãos brasileiros trabalhando em território boliviano, mas que residem no Brasil e vice-versa.

Ademais, as áreas "interligadas" entre as cidades - Brasiléia, Epitaciolândia e Cobija (cidade boliviana), formam o segundo maior aglomerado urbano de toda a região amazônico - acreana (um continuum urbano) sob influência da Zona de Livre Comércio da cidade boliviana (REBOUÇAS; ALMEIDA; SILVA, 2008, p. 234)

A fronteira entre Brasiléia e Cobija é caracterizada por diversos fatores como seus elementos físicos, na qual sua delimitação se dá pelo rio Acre e por sua forte dinâmica econômica, que movimenta a economia local, sob influência da Zona de Livre Comércio da cidade de Cobija. Esses aspectos configuram a cidade de Brasiléia um potencial centro econômico.

\section{CONSIDERAÇÕES FINAIS}

O presente trabalho procurou evidenciar as experiências vivenciadas em campo acerca dos aspectos econômicos, sociais, culturais e ambientais no baixo e no alto acre, através da aula de campo interdisciplinar organizada entre as disciplinas de geografia do acre e geoecologia, desenvolvimento e sustentabilidade.

A experiência nos permitiu conhecer de forma mais profunda a história acreana através das visitas a pontos históricos e falas de pessoas que vivenciaram momentos históricos da trajetória acreana, além de relatos que evidenciaram a dinâmica da tríplice fronteira: brasil peru - Bolívia.

A interdisciplinaridade nos proporcionou relacionar aspectos tanto históricos quanto ambientais dos lugares visitados, interagindo com o que já tinha sido evidenciado em sala de aula. dessa forma, a aula de campo contribuiu significativamente para a construção do conhecimento a respeito do território fronteiriço acreano e suas diversas características, nos levando a um maior conhecimento do estado. 


\section{REFERÊNCIAS}

ACRE. Governo do Estado do Acre. Programa Estadual de Zoneamento Ecológico-Econômico do Estado do Acre. Zoneamento Ecológico-Econômico do Acre Fase II: documento Síntese - Escala 1:250.000. Rio Branco: SEMA, 2006. 354p.

HAESBAERT, R.; PORTO-GONÇALVES, C. W. A des-ordem política mundial: os novos espaços do poder. In: A nova des-ordem mundial. São Paulo: Editora UNESP, 2006. p.51-83.

FARIAS, C. S.; ARAÚJO, J. J. C. N. O agronegócio da cana-de-açúcar no estado do acre: o incentivo estatal, a questão do campesinato e as condições de trabalho. Revista Trabalho Necessário, ano 9, n. 12, 2011.

FISCHER, A.; FIRKOWSKI, O. Lúcia C.; Spósito, E. Indústria, ordenamento do território e transportes - a contribuição de André Fischer Categoria. Expressão Popular, 2008.

RODRIGUES, A. B.; OTAVIANO, C. A. Guia metódologico de trabalho de campo em Geografia . Geografia, Londrina, v. 10, n. 1, p. 35-43, jan./jun. 2001.

SILVA, J. G. da; GROSSI, M. E. Del. O novo rural Brasileiro. Oficina de atualização temática. Campinas. p. 165-173.

SILVA, S. S. da. Geografia da luta pela terra: conflitos e resistência camponesa acreana. In: ACRE: uma visão temática de sua geografia. Rio Branco: EDUFAC, 2008. p. 175-188.

SILVA, S. S. da. O desenvolvimento acreano em questão: contexto histórico e especificidade microrregião. In: REBOUÇAS, F.; ALMEIDA, L. F. de; SILVA, S. S. da. ACRE: uma visão temática de sua geografia. Rio Branco: EDUFAC, 2008. p. 214-244.

TEIXEIRA, N. F. F.; SILVA, E. V. da; FARIAS, J. F. Geoecologia das paisagens e planejamento ambiental: discussão teórica e metodológica para análise ambiental. Planeta Amazônia: Revista internacional de Direito Ambiental e Políticas Públicas. Macapá, n. 9, 2017. p. 147-158.

THIESEN, J. da S. A interdisciplinaridade como um movimento articulador no processo ensino-aprendizagem. Revista Brasileira de Educação,Rio de Janeiro, v. 13, n. 39, 2008. 